\title{
Quantifying cooperative intermolecular interactions for improved carbon dioxide capture materials
}

\author{
Katrina M. de Lange and Joseph R. Lane ${ }^{\text {a) }}$ \\ Department of Chemistry, University of Waikato, Private Bag 3105, Hamilton 3240, New Zealand
}

(Received 25 May 2011; accepted 20 July 2011; published online 11 August 2011)

\begin{abstract}
We have optimized the geometry and calculated interaction energies for over 100 different complexes of $\mathrm{CO}_{2}$ with various combinations of electron accepting (Lewis acid) and electron donating (Lewis base) molecules. We have used the recently developed explicitly correlated coupled cluster singles doubles and perturbative triples [CCSD(T)-F12] methods and the associated VXZ-F12 (where X $=\mathrm{D}, \mathrm{T}, \mathrm{Q}$ ) basis sets. We observe only modest changes in the geometric parameters of $\mathrm{CO}_{2}$ upon complexation, which suggests that the geometry of $\mathrm{CO}_{2}$ adsorbed in a nanoporous material should be similar to that of $\mathrm{CO}_{2}$ in gas phase. When $\mathrm{CO}_{2}$ forms a complex with two Lewis acids via the two electron rich terminal oxygen atoms, the interaction energy is less than twice what would be expected for the same complex involving a single Lewis acid. We consider a series of complexes that exhibit simultaneous $\mathrm{CO}_{2}$-Lewis acid and $\mathrm{CO}_{2}$-Lewis base intermolecular interactions, with total interaction energies spanning $14.1-105.9 \mathrm{~kJ} \mathrm{~mol}^{-1}$. For these cooperative complexes, we find that the total interaction energy is greater than the sum of the interaction energies of the constituent complexes. Furthermore, the intermolecular distances of the cooperative complexes are contracted as compared to the constituent complexes. We suggest that metal-organic-framework or similar nanoporous materials could be designed with adsorption sites specifically tailored for $\mathrm{CO}_{2}$ to allow cooperative intermolecular interactions, facilitating enhanced $\mathrm{CO}_{2}$ adsorption. (C) 2011 American Institute of Physics. [doi:10.1063/1.3624363]
\end{abstract}

\section{INTRODUCTION}

Any serious effort to reduce anthropogenic carbon dioxide $\left(\mathrm{CO}_{2}\right)$ emissions must contend with the geopolitical and economic reality that fossil fuels will continue to make a dominant contribution to the world's energy supply for decades to come. ${ }^{1}$ This makes development of scalable, cost-effective $\mathrm{CO}_{2}$ capture technologies of equal importance to innovations in renewable energy resources over the near future. ${ }^{2}$ Furthermore, captured $\mathrm{CO}_{2}$ is potentially a cheap and green carbon source that can be converted into a variety of valuable organic molecules. ${ }^{3-5}$

Metal organic framework (MOF) materials are a relatively new class of nanoporous crystalline compounds that demonstrate promising ability as physical adsorbents for the separation of gases, including $\mathrm{CO}_{2}$ (see, for example, Refs. 6-9). However, current MOF materials do not yet show the necessary selectivity for $\mathrm{CO}_{2}$ from combustion exhaust gas mixtures. ${ }^{10}$ In particular, very little is known about adsorption of $\mathrm{CO}_{2}$ in the presence of $\mathrm{H}_{2} \mathrm{O}$, the co-product of combustion. ${ }^{1,11} \mathrm{CO}_{2}$ has previously been found to bind to MOF materials at either electron deficient open metal adsorption sites via the electron rich terminal oxygen atom ${ }^{12-14}$ or to electron rich adsorption sites via the electron deficient central carbon atom. ${ }^{9,15,16}$ We propose that MOF adsorption sites which allow simultaneous interaction of the electron rich terminal oxygen atoms and the electron deficient central carbon atom of $\mathrm{CO}_{2}$ could be designed to exploit so-called cooper-

\footnotetext{
${ }^{a)}$ Electronic mail: jlane@waikato.ac.nz.
}

ative intermolecular interactions, increasing the total adsorption strength.

The use of supercritical $\mathrm{CO}_{2}$ as a "green solvent" for industrial processes has resulted in a number of recent experimental ${ }^{17-21}$ and theoretical ${ }^{18-24}$ investigations concerning the fundamental intermolecular interactions of $\mathrm{CO}_{2}$. For molecules containing carbonyl functional groups, $\mathrm{CO}_{2}$ demonstrates simultaneous Lewis acid-Lewis base $\mathrm{R}_{2} \mathrm{C}=\mathrm{O} \cdots \mathrm{CO}_{2}$ and hydrogen bonding interactions $\mathrm{CH} \cdots \mathrm{O}=\mathrm{C}=\mathrm{O} \cdot{ }^{17,20,21,24}$ These two simultaneous intermolecular interactions work cooperatively to strengthen the total interaction. ${ }^{17}$ Similar cooperative intermolecular interactions have also been observed for $\mathrm{CO}_{2}$ complexes with dimethyl ether and 1,2, dimethoxyethane $\left[\left(\mathrm{CH}_{3}\right)_{2} \mathrm{O} \cdots \mathrm{CO}_{2}\right.$ and $\left.\mathrm{CH} \cdots \mathrm{O}=\mathrm{C}=\mathrm{O}\right],{ }^{19,21}$ small fluorinated alkanes ( $\mathrm{RF} \cdots \mathrm{CO}_{2}$ and $\mathrm{CH} \cdots \mathrm{O}=\mathrm{C}=\mathrm{O}$ ), ${ }^{22}$ and various nitrogen containing Lewis bases $\left(\mathrm{N} \cdots \mathrm{CO}_{2}\right.$ and $\mathrm{CH} \cdots \mathrm{O}=\mathrm{C}=\mathrm{O}){ }^{25,26}$ These previous works conclusively demonstrate that $\mathrm{CO}_{2}$ is able to form cooperative intermolecular interactions but they do not quantify the strength of the individual Lewis acid-Lewis base or hydrogen bonding interactions. As a consequence, it is not yet known how strongly cooperative interactions affect the total interaction energy and intermolecular distance(s) of $\mathrm{CO}_{2}$ complexes.

In the present work, we investigate over 100 different complexes involving $\mathrm{CO}_{2}$ with various combinations of electron accepting (Lewis acid) and electron donating (Lewis base) molecules. We consider a range of different donor and acceptor molecules of various strengths that contain first and second row elements. We optimize the geometry and 
calculate the interaction energy for each complex using explicitly correlated coupled cluster methods. We impose a few minor geometric constraints on the complexes to simplify interpretation of the intermolecular interactions and to allow more systematic investigation of the nature of cooperative interactions involving $\mathrm{CO}_{2}$. Our primary objective is to quantify the effect of cooperative interactions on the adsorption strength and optimal intermolecular distance(s) for $\mathrm{CO}_{2}$ complexes to ultimately facilitate a more rational design of $\mathrm{MOF}$ materials with adsorption sites specifically tailored for $\mathrm{CO}_{2}$. The present work complements some recent DFT and MP2 studies that have investigated the interactions of $\mathrm{CO}_{2}$ with potential organic framework linker molecules. ${ }^{26-28}$

\section{THEORETICAL METHODS}

We have optimized the geometries of all complexes and their constituent monomers using the explicitly correlated CCSD(T)-F12 methods as implemented in MOLPRO 2010.1 (Refs. 29 and 30) and the VXZ-F12 (where X = D,T,Q) orbital basis sets. ${ }^{31}$ Recently, we showed that interaction energies and intermolecular distances of weakly bound complexes obtained with this approach are in excellent agreement with the CCSD(T)/CBS limit. ${ }^{32,33}$

Density fitting approximations $\mathrm{s}^{34,35}$ and the resolution of the identity approximation were utilized in all explicitly correlated calculations with the default auxiliary basis sets ${ }^{36-38}$ for all atoms except Li. For Li, the def2-TZVPP/JKFIT auxiliary basis set was used. The default complementary auxiliary basis set singles correction was applied, ${ }^{29}$ which substantially improves the accuracy of the Hartree-Fock (HF) contributions particularly with smaller orbital basis sets. ${ }^{39}$ The diagonal, fixed amplitude 3C(FIX) ansatz was used, which is orbital invariant, size consistent, and free of geminal basis set superposition error. ${ }^{40-42}$ The default CCSD-F12 correlation factor $\left[(1 / \beta) e^{-\beta r_{12}}\right.$, where $\left.\beta=1\right]$ was used in all explicitly correlated calculations. We have not scaled the triples contribution in our $\operatorname{CCSD}(\mathrm{T})-\mathrm{F} 12$ calculations.

Unless specified all coupled cluster calculations assume a frozen core $(\mathrm{B}: 1 s, \mathrm{C}: 1 s ; \mathrm{N}: 1 s ; \mathrm{O}: 1 s ; \mathrm{F}: 1 s ; \mathrm{P}: 1 s, 2 s, 2 p$; $\mathrm{S}: 1 s, 2 s, 2 p ; \mathrm{Cl}: 1 s, 2 s, 2 p)$ and were performed using MOLPRO 2010.1. ${ }^{30}$ The optimization threshold criteria were set to: gradient $=1 \times 10^{-6}$ a.u., stepsize $=1 \times 10^{-6}$ a.u., energy $=1 \times 10^{-8}$ a.u. All single point energies were converged to $1 \times 10^{-9}$ a.u.

We calculate atomic charges using the natural bond orbital (NBO) analysis in GAUSSIAN 09 with the B3LYP/augcc-pVTZ method using the CCSD(T)-F12a/VDZ-F12 optimized geometries. ${ }^{43}$

\section{RESULTS AND DISCUSSION}

As shown in Fig. $1, \mathrm{CO}_{2}$ is able to form simultaneous intermolecular interactions via the electron rich terminal oxygen atoms $(\mathrm{O} \cdots \mathrm{X})$ and the electron deficient central carbon atom (C...Y). These simultaneous interactions work cooperatively such that the total interaction energy of a complex is different to the sum of the individual parts. Within this context, we define the magnitude of the coop-



FIG. 1. A simplified model of simultaneous intermolecular interactions in $\mathrm{X}_{2}-\mathrm{CO}_{2}-\mathrm{Y}$ complexes.

erative interaction as being the difference (either positive or negative) between the interaction energy of the total complex and the interaction energy of the constituent individual complexes. For example, if the interaction energy of $\mathrm{X}_{2}-\mathrm{CO}_{2}-\mathrm{Y}$ was $40 \mathrm{~kJ} \mathrm{~mol}^{-1}$ and the interaction energies of $\mathrm{X}_{2}-\mathrm{CO}_{2}$ and $\mathrm{CO}_{2}-\mathrm{Y}$ were 20 and $15 \mathrm{~kJ} \mathrm{~mol}^{-1}$, respectively, the magnitude of the cooperative interaction would be $+5 \mathrm{~kJ} \mathrm{~mol}^{-1}$. It is important to note that our definition of cooperative interaction assumes that the effect of basis set superposition error (BSSE) is negligible. While this requirement can not be satisfied with any finite basis set, the magnitude of BSSE obtained with explicitly correlated CCSD(T)-F12 methods is much smaller than with conventional $\operatorname{CCSD}(\mathrm{T}){ }^{33}$ For example, the difference between the interaction energy of $\mathrm{H}_{2} \mathrm{O}-\mathrm{CO}_{2}$ obtained with and without counterpoise correction is $0.8 \mathrm{~kJ} \mathrm{~mol}^{-1}$ for CCSD(T)-F12a/VDZ-F12 and $3.2 \mathrm{~kJ} \mathrm{~mol}^{-1}$ for $\operatorname{CCSD}(\mathrm{T}) /$ aug-cc-pVDZ. The difference in the corresponding optimized intermolecular distance of $\mathrm{H}_{2} \mathrm{O}-$ $\mathrm{CO}_{2}$ obtained with and without counterpoise correction is $0.013 \AA$ for $\operatorname{CCSD}(\mathrm{T})-\mathrm{F} 12 \mathrm{a} / \mathrm{VDZ}-\mathrm{F} 12$ and $0.089 \AA$ for $\operatorname{CCSD}(T) /$ aug-cc-pVDZ. Furthermore, the absolute values of the non-counterpoise corrected CCSD(T)-F12a/VDZ-F12 interaction energy $\left(12.4 \mathrm{~kJ} \mathrm{~mol}^{-1}\right)$ and intermolecular distance $\left(2.761 \AA\right.$ ) for $\mathrm{H}_{2} \mathrm{O}-\mathrm{CO}_{2}$ are in better agreement with the $\operatorname{CCSD}(\mathrm{T}) / \mathrm{CBS}$ limits $\left(12.2 \mathrm{~kJ} \mathrm{~mol}^{-1}\right.$ and $\left.2.755 \AA\right)$ than the counterpoise corrected values $\left(11.5 \mathrm{~kJ} \mathrm{~mol}^{-1}\right.$ and 2.774 $\AA$ ). ${ }^{33}$ Finally, it should also be noted that the magnitude of the cooperative interaction in the electronic energy of our model adsorption site will not necessarily be the same as the magnitude of the cooperative interaction for the enthalpy of adsorption $\left(\Delta H_{a d s}\right)$ of a bulk MOF material that incorporates the same adsorption site. This work, therefore, is a "proof of concept" that cooperative intermolecular interactions may facilitate enhanced $\mathrm{CO}_{2}$ adsorption in MOF or similar nanoporous materials.

\section{$(\mathrm{HF})_{n}-\mathrm{CO}_{2}$}

We begin by investigating the suitability of the CCSD(T)F12 methods to accurately calculate interaction energies and hence the magnitude of cooperative interactions in a model system consisting of $(\mathrm{HF})_{n}-\mathrm{CO}_{2}$ (where $n=1-4,6$ ). We consider two $\mathrm{CO}_{2}$-Lewis acid complexes with either 1 or $2 \mathrm{HF}$ molecules forming hydrogen bond(s) with the electron rich terminal oxygen atom(s) of $\mathrm{CO}_{2}$ and three $\mathrm{CO}_{2}$-Lewis base complexes with either 1,2 , or $4 \mathrm{HF}$ molecules interacting via the electron rich fluorine atom(s) and the electron deficient central carbon atom of $\mathrm{CO}_{2}$. We also consider three cooperative complexes in which two HF molecules form hydrogen 
TABLE I. CCSD(T)-F12 interaction energies (in $\mathrm{kJ} \mathrm{mol}^{-1}$ ) for $(\mathrm{HF})_{n}{ }^{-}$ $\mathrm{CO}_{2} \cdot{ }^{\mathrm{a}}$

\begin{tabular}{|c|c|c|c|c|c|c|}
\hline & \multicolumn{2}{|c|}{ VDZ-F12 } & \multicolumn{2}{|c|}{ VTZ-F12 } & \multicolumn{2}{|c|}{ VQZ-F12 } \\
\hline & F12a & $\mathrm{F} 12 \mathrm{~b}$ & F12a & $\mathrm{F} 12 \mathrm{~b}$ & F12a & $\mathrm{F} 12 \mathrm{~b}$ \\
\hline \multicolumn{7}{|c|}{$\mathrm{CO}_{2}$-Lewis acid complexes: ${ }^{\mathrm{b}}$} \\
\hline$(\mathrm{HF})-\mathrm{CO}_{2}$ & 12.11 & 12.00 & 12.22 & 12.24 & 12.16 & 12.19 \\
\hline$(\mathrm{HF})_{2}-\mathrm{CO}_{2}$ & 20.18 & 20.00 & 20.39 & 20.43 & 20.26 & 20.32 \\
\hline \multicolumn{7}{|c|}{$\mathrm{CO}_{2}$-Lewis base complexes: $^{\mathrm{c}}$} \\
\hline$(\mathrm{HF})-\mathrm{CO}_{2}$ & 5.60 & 5.50 & 5.51 & 5.49 & 5.47 & 5.47 \\
\hline$(\mathrm{HF})_{2}-\mathrm{CO}_{2}$ & 9.60 & 9.42 & 9.39 & 9.36 & 9.34 & 9.33 \\
\hline$(\mathrm{HF})_{4}-\mathrm{CO}_{2}$ & 10.99 & 10.67 & 10.55 & 10.51 & 10.50 & 10.50 \\
\hline \multicolumn{7}{|c|}{ Cooperative complexes: } \\
\hline$(\mathrm{HF})_{3}-\mathrm{CO}_{2}$ & 32.62 & 32.29 & 32.77 & 32.80 & 32.60 & 32.65 \\
\hline$(\mathrm{HF})_{4}-\mathrm{CO}_{2}$ & 43.24 & 42.78 & 43.30 & 43.30 & 43.10 & 43.15 \\
\hline$(\mathrm{HF})_{6}-\mathrm{CO}_{2}$ & 57.12 & 56.43 & & & & \\
\hline \multicolumn{7}{|c|}{ Cooperative interaction $^{\mathrm{d}}$} \\
\hline$(\mathrm{HF})_{3}-\mathrm{CO}_{2}$ & +6.83 & +6.79 & +6.88 & +6.87 & +6.87 & +6.87 \\
\hline$(\mathrm{HF})_{4}-\mathrm{CO}_{2}$ & +13.45 & +13.36 & +13.52 & +13.52 & +13.51 & +13.51 \\
\hline$(\mathrm{HF})_{6}-\mathrm{CO}_{2}$ & +25.94 & +25.76 & & & & \\
\hline
\end{tabular}

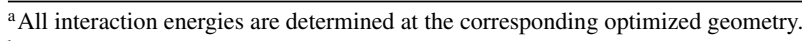

${ }^{\mathrm{b}}$ Complexes where $\mathrm{CO}_{2}$ acts as an electron donor.

${ }^{\mathrm{c}}$ Complexes where $\mathrm{CO}_{2}$ acts as an electron acceptor.

${ }^{\mathrm{d}}$ Difference between the interaction energy of a cooperative complex and the interaction energy of the constituent $\mathrm{CO}_{2}$-Lewis acid and $\mathrm{CO}_{2}$-Lewis base complexes. See text for details.

bonds to the two oxygen atoms of $\mathrm{CO}_{2}$ and either 1,2 , or 4 $\mathrm{HF}$ molecules interact via the fluorine atom(s) with the central carbon atom of $\mathrm{CO}_{2}$. Representative images of all $(\mathrm{HF})_{n}-\mathrm{CO}_{2}$ (where $n=1-4,6$ ) complexes optimized with the $\operatorname{CCSD(T)-~}$ F12a/VDZ-F12 method are included in Fig. S1 of the supplementary material. ${ }^{44}$

In Table I, we present CCSD(T)-F12a and $\operatorname{CCSD}(\mathrm{T})-$ $\mathrm{F} 12 \mathrm{~b}$ interaction energies for $(\mathrm{HF})_{n}-\mathrm{CO}_{2}$ (where $n=1-4,6$ ) obtained with the VDZ-F12, VTZ-F12 and VQZ-F12 basis sets. We have previously found that $\operatorname{CCSD}(\mathrm{T})-\mathrm{F} 12 \mathrm{~b} / \mathrm{VQZ}-$ F12 interaction energies are in exceptionally good agreement with the $\operatorname{CCSD}(\mathrm{T}) / \mathrm{CBS}$ limit so we consider this the benchmark for comparison. ${ }^{32,33}$ Overall, we find that the calculated interaction energies converge as the cardinal number of the basis set increases from VDZ-F12 to VQZ-F12, although there is some small oscillation in some of the results. We find there to be relatively small differences between the CCSD(T)-F12a and CCSD(T)-F12b interaction energies obtained with a given basis set and not surprisingly these differences are largest for the VDZ-F12 basis set and smallest for the VQZ-F12 basis set. As some of the complexes considered in the subsequent subsections are relatively large, we are, however, restricted to use of the VDZ-F12 basis set. We find that interaction energies of the $\mathrm{CO}_{2}$-Lewis acid complexes are slightly underestimated with the VDZ-F12 basis set whereas interaction energies of the $\mathrm{CO}_{2}$-Lewis base complexes are slightly overestimated. For both types of complexes, these discrepancies become larger as the number of HF molecules increases. Interestingly, the $\operatorname{CCSD}(\mathrm{T})-\mathrm{F} 12 \mathrm{a}$ method appears to better describe the $\mathrm{CO}_{2}$-Lewis acid complexes and the $\mathrm{CCSD}(\mathrm{T})-\mathrm{F} 12 \mathrm{~b}$ method appears to better describe the $\mathrm{CO}_{2}$ Lewis base complexes with the VDZ-F12 basis set. For the cooperative complexes where both types of intermolecular interactions are present, the CCSD(T)-F12a/VDZ-F12 interaction energies are appreciably closer to the $\operatorname{CCSD}(\mathrm{T})$ F12b/VQZ-F12b results as compared to the $\operatorname{CCSD(T)-~}$ F12b/VDZ-F12 interaction energies. As a consequence, we find that the magnitude of the cooperative interaction determined with CCSD(T)-F12a/VDZ-F12 method is slightly $\left(<0.1 \mathrm{~kJ} \mathrm{~mol}^{-1}\right.$ difference) more accurate than if determined with the CCSD(T)-F12b/VDZ-F12 method. This result is consistent with other theoretical investigations that recommend use of the CCSD(T)-F12a method with smaller VDZF12 and VTZ-F12 basis sets and use of the CCSD(T)-F12b method with the larger VQZ-F12 basis set. ${ }^{32,45}$ It follows that all geometry optimizations and interaction energies in the rest of this investigation are determined using the CCSD(T)F12a/VDZ-F12 method. This method is expected to give interaction energies for all three types of complexes and the magnitude of the cooperative interaction to within a few tenths of a kJ mol ${ }^{-1}$ of the CCSD(T)-F12b/VQZ-F12 result.

\section{$\mathrm{CO}_{2}$-Lewis acid complexes}

In Table II, we present CCSD(T)-F12a/VDZ-F12 interaction energies, optimized intermolecular distances, and the magnitude of the cooperative interaction for a series of $\mathrm{X}_{n^{-}}$ $\mathrm{CO}_{2}$ (where $n=1$ or 2 ) complexes. We consider 20 Lewis acid molecules that bind to $\mathrm{CO}_{2}$ via $\mathrm{O} \cdots \mathrm{X}$ interactions involving four different electron deficient atoms $(\mathrm{H}, \mathrm{Li}, \mathrm{B}, \mathrm{Al})$. In Fig. 2, we show a representative image of the $\left(\mathrm{H}_{2} \mathrm{O}\right)_{2}-\mathrm{CO}_{2}$ complex with the optimized geometries of all other $\mathrm{X}-\mathrm{CO}_{2}$ and $\mathrm{X}_{2}-\mathrm{CO}_{2}$ complexes given in Figs. S2-S4 of the supplementary material. ${ }^{44}$ As our primary motivation is to ascertain the effect of "cooperative interactions" on $\mathrm{CO}_{2}$, we have introduced some minor geometric constraints to simplify this interpretation. We assume that all diatomic and linear molecules bind $\mathrm{CO}_{2}$ in a linear fashion with either $C_{\infty v}(\mathrm{X}=1)$ or $D_{\infty h}$ $(\mathrm{X}=2)$ symmetry. For the polyatomic hydrogen bonding molecules, we restrict the hydrogen bond to be linear [e.g., $\theta(\mathrm{C}=\mathrm{O} \cdots \mathrm{H})$ and $\theta(\mathrm{O} \cdots \mathrm{HO})$ of $\mathrm{H}_{2} \mathrm{O}-\mathrm{CO}_{2}$ are $\left.180^{\circ}\right]$ and orientate the two $\mathrm{X}$ molecules to be on the opposite side to each other to minimize any potential $\mathrm{X} \cdot \mathrm{X}$ interactions. For the boron and aluminum hydrides and halides, we assume that the $\theta(\mathrm{C}=\mathrm{O} \cdots \mathrm{B})$ or $\theta(\mathrm{C}=\mathrm{O} \cdots \mathrm{Al})$ angle is linear and that the two electron deficient groups are in a staggered orientation $\left(D_{3 h}\right.$ symmetry). All other geometric parameters are optimized.

As expected, there are only modest differences between the geometric parameters of $\mathrm{CO}_{2}$ as a monomer and in the $\mathrm{X}-\mathrm{CO}_{2}$ and $\mathrm{X}_{2}-\mathrm{CO}_{2}$ complexes. For $\mathrm{X}-\mathrm{CO}_{2}$, we find that the bonded $\mathrm{R}(\mathrm{C}=\mathrm{O})_{b}$ distance is slightly elongated and the free $\mathrm{R}(\mathrm{C}=\mathrm{O})_{f}$ distance is slightly contracted, as compared to $\mathrm{R}(\mathrm{C}=\mathrm{O})$ in $\mathrm{CO}_{2}$ monomer. Furthermore, there is a strong correlation between the interaction energy of a complex and the values of both $\mathrm{R}(\mathrm{C}=\mathrm{O})_{b}$ and $\mathrm{R}(\mathrm{C}=\mathrm{O})_{f}$ (Figs. S5 and S6 of the supplementary material $).{ }^{44}$ These results are consistent with the Lewis acid essentially polarizing the $\mathrm{CO}_{2}$ molecule so that electron density moves from a non-bonding orbital of the free $\mathrm{C}=\mathrm{O}$ group into an anti-bonding orbital of the bonded $\mathrm{C}=\mathrm{O}$ group (Table $\mathrm{S} 1$ of the supplementary material). ${ }^{44}$ In 
TABLE II. CCSD(T)-F12a/VDZ-F12 interaction energies (in kJ mol ${ }^{-1}$ ) and selected geometric parameters (in $\AA$ ) for a series of $\mathrm{CO}_{2}$-Lewis acid complexes.

\begin{tabular}{|c|c|c|c|c|c|c|}
\hline \multirow[b]{2}{*}{ Molecule } & \multicolumn{2}{|c|}{$\mathrm{X}-\mathrm{CO}_{2}$} & \multicolumn{4}{|c|}{$\mathrm{X}_{2}-\mathrm{CO}_{2}$} \\
\hline & Int. energy & $\mathrm{R}(\mathrm{O} \cdots \mathrm{X})^{\mathrm{a}}$ & Int. energy & $\mathrm{R}(\mathrm{O} \cdots \mathrm{X})^{\mathrm{a}}$ & $\mathrm{R}(\mathrm{X} \cdots \mathrm{X})^{\mathrm{b}}$ & Coop. Int. ${ }^{c}$ \\
\hline $\mathrm{HNC}$ & 12.4 & 2.058 & 19.6 & 2.123 & 6.568 & -5.1 \\
\hline $\mathrm{HF}$ & 12.1 & 1.981 & 20.2 & 2.037 & 6.395 & -4.0 \\
\hline $\mathrm{HCOOH}$ & 10.5 & 2.071 & 18.7 & 2.114 & 6.551 & -2.3 \\
\hline $\mathrm{C}_{4} \mathrm{H}_{5} \mathrm{~N}$ & 8.6 & 2.217 & 15.2 & 2.255 & 6.835 & -2.1 \\
\hline $\mathrm{HCN}$ & 8.3 & 2.269 & 13.5 & 2.324 & 6.973 & -3.1 \\
\hline $\mathrm{OH}$ & 8.2 & 2.182 & 14.2 & 2.228 & 6.779 & -2.2 \\
\hline $\mathrm{HCl}$ & 7.9 & 2.217 & 14.2 & 2.256 & 6.836 & -1.6 \\
\hline $\mathrm{CH}_{3} \mathrm{OH}$ & 7.4 & 2.200 & 13.6 & 2.252 & 6.786 & -1.3 \\
\hline $\mathrm{H}_{2} \mathrm{O}$ & 7.0 & 2.221 & 12.5 & 2.252 & 6.828 & -1.4 \\
\hline $\mathrm{C}_{6} \mathrm{H}_{6}$ & 3.1 & 2.603 & 6.1 & 2.605 & 7.536 & -0.0 \\
\hline $\mathrm{CH}_{4}$ & 1.7 & 2.743 & 3.4 & 2.744 & 7.815 & -0.0 \\
\hline $\mathrm{LiCl}$ & 37.2 & 1.990 & 43.3 & 2.093 & 6.504 & -31.1 \\
\hline $\mathrm{LiH}$ & 32.4 & 2.008 & 39.8 & 2.104 & 6.526 & -25.1 \\
\hline $\mathrm{LiF}$ & 31.4 & 2.028 & 37.7 & 2.127 & 6.572 & -25.1 \\
\hline $\mathrm{BF}_{3}$ & 9.9 & 2.674 & 18.5 & 2.706 & 7.736 & -1.3 \\
\hline $\mathrm{BH}_{3}$ & 8.4 & 2.518 & 16.0 & 2.550 & 7.423 & -0.8 \\
\hline $\mathrm{BCl}_{3}$ & 7.3 & 3.042 & 14.7 & 3.044 & 8.413 & +0.1 \\
\hline $\mathrm{AlF}_{3}$ & 50.8 & 2.027 & 67.8 & 2.167 & 6.646 & -33.7 \\
\hline $\mathrm{AlCl}_{3}$ & 37.2 & 2.065 & 47.4 & 2.290 & 6.896 & -27.1 \\
\hline $\mathrm{AlH}_{3}$ & 24.5 & 2.229 & 36.7 & 2.385 & 7.088 & -12.3 \\
\hline
\end{tabular}

${ }^{\mathrm{a}}$ Distance from the electron rich oxygen atom of $\mathrm{CO}_{2}$ to the electron deficient atom of the acceptor molecule.

${ }^{\mathrm{b}}$ Distance between the electron deficient atoms of the two acceptor molecules.

${ }^{\mathrm{c}}$ Interaction energy of $\mathrm{X}_{2}-\mathrm{CO}_{2}$ subtract interaction energy of two times the $\mathrm{X}-\mathrm{CO}_{2}$ interaction energy.

contrast we find that the $\mathrm{R}(\mathrm{C}=\mathrm{O})_{b}$ distance for $\mathrm{X}_{2}-\mathrm{CO}_{2}$ is actually contracted as compared to $\mathrm{R}(\mathrm{C}=\mathrm{O})$ in $\mathrm{CO}_{2}$ monomer. We attribute this result to electron density transfer from the non-bonding orbitals of $\mathrm{CO}_{2}$ to the electron deficient atom of the Lewis acid (Table $\mathrm{S} 1$ of the supplementary material). ${ }^{44}$ The value of $\mathrm{R}(\mathrm{C}=\mathrm{O})_{b}$ for $\mathrm{X}_{2}-\mathrm{CO}_{2}$ is again very well correlated with the interaction energy of the complex and is shortest for strongly bonded complexes (Fig. S7 of the supplementary material). ${ }^{44}$

With exception of the $\mathrm{BCl}_{3}$ results, we find that the cooperative interaction of all $\mathrm{X}_{2}-\mathrm{CO}_{2}$ complexes is negative. That is the total interaction energy is less than two times the interaction energy of the $\mathrm{X}-\mathrm{CO}_{2}$ complex. This result can be rationalized by considering the atomic charges of oxygen atoms of $\mathrm{CO}_{2}$ from NBO analysis (Table $\mathrm{S} 1$ of the supplementary material). ${ }^{44}$ Upon forming the $\mathrm{X}-\mathrm{CO}_{2}$ complex, the non-bonded oxygen atom of $\mathrm{CO}_{2}$ becomes less electron rich and is hence less attractive to the electron deficient atom of the second $\mathrm{X}$ molecule in $\mathrm{X}_{2}-\mathrm{CO}_{2}$. The magnitude of the cooperative interaction is well correlated with the interaction energy of $\mathrm{X}-\mathrm{CO}_{2}$ and is large for strongly bound complexes such as $\left(\mathrm{AlF}_{3}\right)_{2}-\mathrm{CO}_{2}$ and small for weakly bound complexes such


FIG. 2. The CCSD(T)-F12a/VDZ-F12 optimized geometry of $\left(\mathrm{H}_{2} \mathrm{O}\right)_{2}-\mathrm{CO}_{2}$. as $\left(\mathrm{CH}_{4}\right)_{2}-\mathrm{CO}_{2}$ (Fig. $\mathrm{S} 8$ of the supplementary material). ${ }^{44}$ We find that the $\mathrm{R}(\mathrm{O} \cdots \mathrm{X})$ intermolecular distance for $\mathrm{X}_{2}-$ $\mathrm{CO}_{2}$ is longer than for $\mathrm{X}-\mathrm{CO}_{2}$ and this difference can be thought of as the primary geometric effect of the cooperative interactions. The difference between $\mathrm{R}(\mathrm{O} \cdots \mathrm{X})$ for $\mathrm{X}_{2}-$ $\mathrm{CO}_{2}$ and $\mathrm{X}-\mathrm{CO}_{2}$ correlates reasonably well with the magnitude of the cooperative interaction (Fig. S9 of the supplementary material). ${ }^{44}$ This correlation is more pronounced if the results of the very strongly bonded lithium and aluminum hydrides and halides are excluded (Fig. S10 of the supplementary material). ${ }^{44}$

The optimized $\mathrm{R}(\mathrm{X} \cdots \mathrm{X})$ distances for $\mathrm{X}_{2}-\mathrm{CO}_{2}$ shown in Table II represent the optimal dimensions for a $\mathrm{CO}_{2}$ adsorption site based on two equivalent electron deficient atoms through $\mathrm{O} \cdots \mathrm{X}$ intermolecular interactions. We find that there is considerable variation in the $\mathrm{R}(\mathrm{X} \cdots \mathrm{X})$ distance even for the same atom type $(\mathrm{H}, \mathrm{Li}, \mathrm{B}, \mathrm{Al})$ and hence it is not reasonable to generalize the optimal dimensions of an adsorption site based purely on the immediate atom of interaction $\mathrm{O} \cdots \mathrm{X}$. For example, $\mathrm{R}(\mathrm{X} \cdots \mathrm{X})$ is $6.395 \AA$ for $\mathrm{HF}_{2}-\mathrm{CO}_{2}$ and 7.815 $\AA$ for $\left(\mathrm{CH}_{4}\right)_{2}-\mathrm{CO}_{2}$ despite both molecules binding through an electron deficient hydrogen atom.

\section{$\mathrm{CO}_{2}$-Lewis base complexes}

In Table III, we present CCSD(T)-F12a/VDZ-F12 interaction energies, optimized intermolecular distances and the OCO angle of $\mathrm{CO}_{2}$ for a series of $\mathrm{CO}_{2}-\mathrm{Y}$ complexes. We consider 29 different Lewis base molecules that bind to $\mathrm{CO}_{2}$ via $\mathrm{C} \cdots \mathrm{Y}$ interactions involving seven different electron rich atoms $(\mathrm{C}, \mathrm{N}, \mathrm{O}, \mathrm{F}, \mathrm{P}, \mathrm{S}$, and $\mathrm{Cl})$. Each complex adopts 
TABLE III. CCSD(T)-F12a/VDZ-F12 interaction energies (in kJ mol ${ }^{-1}$ ) and selected geometric parameters (in $\AA$ and degrees) for a series of $\mathrm{CO}_{2}$-Lewis base complexes.

\begin{tabular}{|c|c|c|c|c|c|c|c|}
\hline Molecule & Int. energy & $\mathrm{R}(\mathrm{C} \cdots \mathrm{Y})^{\mathrm{a}}$ & $\theta(\mathrm{OCO})$ & Molecule & Int. energy & $\mathrm{R}(\mathrm{C} \cdots \mathrm{Y})^{\mathrm{a}}$ & $\theta(\mathrm{OCO})$ \\
\hline \multicolumn{8}{|c|}{ C-donor } \\
\hline $\mathrm{C}_{3} \mathrm{H}_{4} \mathrm{~N}_{2}{ }^{\mathrm{b}}$ & 19.2 & 2.900 & 175.6 & & & & \\
\hline $\mathrm{HNC}$ & 8.7 & 3.117 & 178.5 & & & & \\
\hline \multicolumn{4}{|c|}{$\mathrm{N}$-donor } & \multicolumn{4}{|c|}{ P-donor } \\
\hline $\mathrm{C}_{5} \mathrm{H}_{5} \mathrm{~N}^{\mathrm{b}}$ & 18.5 & 2.751 & 176.3 & & & & \\
\hline $\mathrm{N}\left(\mathrm{CH}_{3}\right)_{3}{ }^{\mathrm{b}}$ & 18.3 & 2.778 & 176.3 & & & & \\
\hline $\mathrm{C}_{4} \mathrm{H}_{4} \mathrm{~N}_{2}{ }^{\mathrm{b}}$ & 16.6 & 2.787 & 177.3 & & & & \\
\hline $\mathrm{NH}_{3}{ }^{\mathrm{b}}$ & 12.8 & 2.926 & 177.5 & $\mathrm{PH}_{3}$ & 6.3 & 3.536 & 179.2 \\
\hline $\mathrm{CH}_{3} \mathrm{CN}$ & 10.6 & 2.936 & 178.1 & & & & \\
\hline $\mathrm{HCN}$ & 8.9 & 2.976 & 178.5 & $\mathrm{HCP}$ & 2.3 & 3.670 & 180.1 \\
\hline $\mathrm{FCN}$ & 8.4 & 2.981 & 178.7 & & & & \\
\hline $\mathrm{CH}_{2} \mathrm{~N}_{2}$ & 7.6 & 2.967 & 179.1 & & & & \\
\hline \multicolumn{4}{|c|}{ O-donor } & \multicolumn{4}{|c|}{ S-donor } \\
\hline $\mathrm{O}\left(\mathrm{CH}_{3}\right)_{2}{ }^{\mathrm{b}}$ & 17.2 & 2.660 & 177.6 & & & & \\
\hline $\mathrm{OPH}_{3}$ & 13.6 & 2.756 & 177.6 & & & & \\
\hline $\mathrm{C}_{4} \mathrm{H}_{4} \mathrm{O}^{\mathrm{b}}$ & 12.5 & 2.760 & 178.8 & $\mathrm{C}_{4} \mathrm{H}_{4} \mathrm{~S}^{\mathrm{a}}$ & 6.3 & 3.536 & 179.7 \\
\hline $\mathrm{H}_{2} \mathrm{O}$ & 12.4 & 2.761 & 178.2 & & & & \\
\hline$\left(\mathrm{CH}_{3}\right)_{2} \mathrm{CO}$ & 12.1 & 2.765 & 178.2 & & & & \\
\hline $\mathrm{CH}_{2} \mathrm{O}$ & 9.8 & 2.811 & 178.6 & $\mathrm{CH}_{2} \mathrm{~S}$ & 2.3 & 3.387 & 179.9 \\
\hline $\mathrm{OPF}_{3}$ & 9.4 & 2.843 & 178.6 & & & & \\
\hline $\mathrm{CF}_{2} \mathrm{O}$ & 7.0 & 2.891 & 179.2 & & & & \\
\hline $\mathrm{CH}_{2} \mathrm{CO}$ & 6.8 & 2.901 & 179.2 & & & & \\
\hline \multicolumn{4}{|c|}{ F-donor } & \multicolumn{4}{|c|}{ Cl-donor } \\
\hline $\mathrm{LiF}$ & 20.6 & 2.565 & 175.5 & $\mathrm{LiCl}$ & 10.7 & 3.228 & 178.0 \\
\hline $\mathrm{CH}_{3} \mathrm{~F}$ & 7.1 & 2.825 & 179.0 & $\mathrm{CH}_{3} \mathrm{Cl}$ & 3.2 & 3.430 & 179.8 \\
\hline $\mathrm{HF}$ & 5.6 & 2.874 & 179.2 & $\mathrm{HCl}$ & 1.8 & 3.527 & 180.1 \\
\hline
\end{tabular}

${ }^{\mathrm{a}}$ Distance from the electron deficient carbon atom of $\mathrm{CO}_{2}$ to the electron rich atom of the donor molecule.

${ }^{\mathrm{b}}$ Hydrogen atoms adjacent to the primary interaction site permit additional hydrogen bonding interactions to the oxygen atoms of $\mathrm{CO}_{2}$.

either a symmetric " $\mathrm{t}$-shape" structure with both $\mathrm{C}=\mathrm{O}$ bonds of $\mathrm{CO}_{2}$ equivalent (e.g., $\mathrm{C}_{3} \mathrm{H}_{4} \mathrm{~N}_{2}$ ) or an asymmetric "t-shape" structure with the two $\mathrm{C}=\mathrm{O}$ bonds approximately equivalent [e.g., $\mathrm{N}\left(\mathrm{CH}_{3}\right)_{3}$ ]. In Fig. 3, we show a representative image of the $\mathrm{CO}_{2}-\mathrm{C}_{5} \mathrm{H}_{5} \mathrm{~N}$ complex with the optimized geometries of all other $\mathrm{CO}_{2}-\mathrm{Y}$ complexes given in Figs. S11-S13 of the supplementary material. ${ }^{44}$

It is worth noting that many of the complexes that have large interaction energies already exhibit cooperative intermolecular interactions via hydrogen bonding $(\mathrm{OCO} \cdots \mathrm{H})$ to hydrogen atoms adjacent to the electron rich atom. For example, $\mathrm{C}_{3} \mathrm{H}_{4} \mathrm{~N}_{2}, \mathrm{C}_{5} \mathrm{H}_{5} \mathrm{~N}, \mathrm{~N}\left(\mathrm{CH}_{3}\right)_{3}, \mathrm{NH}_{3}, \mathrm{C}_{4} \mathrm{H}_{4} \mathrm{~N}_{2}, \mathrm{O}\left(\mathrm{CH}_{3}\right)_{2}$, and $\mathrm{C}_{4} \mathrm{H}_{4} \mathrm{O}$. This perhaps complicates the interpretation of the strength of the "cooperative interactions" in Table IV (vide infra) as the net effect of simultaneous OCO $\cdots \mathrm{H}$ and $\mathrm{O} \cdot \mathrm{X}$ interactions will likely result in a small positive cooperative effect (Table II). As expected, we find that the interaction energies of the complexes involving second row electron rich atoms $(\mathrm{P}, \mathrm{S}, \mathrm{Cl})$ are generally not as strong as their first row equivalents. This suggests that first row electron rich atoms are a better choice for design of an adsorption site that strongly binds $\mathrm{CO}_{2}$ via the electron deficient central carbon atom.

Overall, there are modest changes in the geometric parameters of $\mathrm{CO}_{2}$ upon formation of the $\mathrm{CO}_{2}-\mathrm{Y}$ complexes.
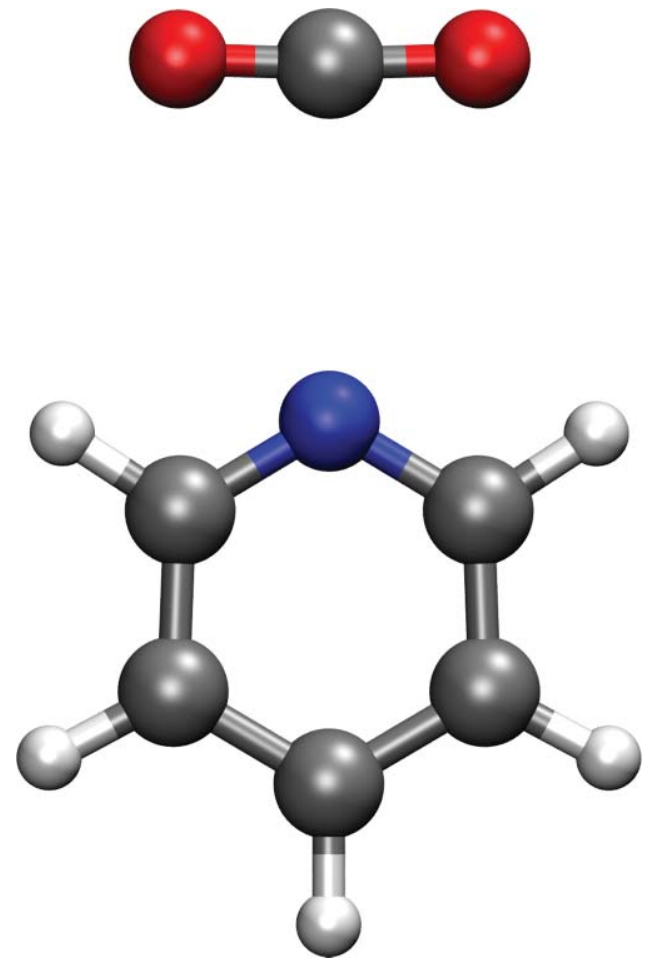

FIG. 3. The CCSD(T)-F12a/VDZ-F12 optimized geometry of $\mathrm{CO}_{2}-\mathrm{C}_{5} \mathrm{H}_{5} \mathrm{~N}$. 
TABLE IV. CCSD(T)-F12a/VDZ-F12 interaction energies (in $\mathrm{kJ} \mathrm{mol}^{-1}$ ) and selected geometric parameters (in $\AA$ ) for cooperatively bonded complexes of the type $(\mathrm{HF})_{2}-\mathrm{CO}_{2}-\mathrm{Y}$.

\begin{tabular}{lccccc}
\hline \hline Molecule & $\begin{array}{c}\text { Int. } \\
\text { energy }\end{array}$ & $\begin{array}{c}\text { Coop. } \\
\text { int. }^{\mathrm{a}}\end{array}$ & Enhancement $^{\mathrm{b}}$ & $\begin{array}{c}\Delta \mathrm{R} \\
(\mathrm{O} \cdots \mathrm{H})^{\mathrm{c}}\end{array}$ & $\begin{array}{c}\Delta \mathrm{R} \\
(\mathrm{C} \cdots \mathrm{Y})^{\mathrm{d}}\end{array}$ \\
\hline $\mathrm{LiF}$ & 66.3 & +25.5 & $63 \%$ & -0.137 & -0.148 \\
$\mathrm{C}_{3} \mathrm{H}_{4} \mathrm{~N}_{2}$ & 58.8 & +19.3 & $49 \%$ & -0.142 & -0.175 \\
$\mathrm{C}_{5} \mathrm{H}_{5} \mathrm{~N}$ & 52.1 & +13.4 & $34 \%$ & -0.109 & -0.110 \\
$\mathrm{LiCl}$ & 48.4 & +17.5 & $57 \%$ & -0.080 & -0.171 \\
$\mathrm{O}_{\left(\mathrm{CH}_{3}\right)_{2}}$ & 47.7 & +10.3 & $28 \%$ & -0.090 & -0.072 \\
$\mathrm{C}_{4} \mathrm{H}_{4} \mathrm{~N}_{2}$ & 46.9 & +10.1 & $27 \%$ & -0.098 & -0.086 \\
$\left(\mathrm{CH}_{3}\right)_{2} \mathrm{CO}$ & 45.4 & +13.1 & $41 \%$ & -0.078 & -0.115 \\
$\mathrm{H}_{2} \mathrm{O}$ & 42.4 & +9.8 & $30 \%$ & -0.072 & -0.078 \\
$\mathrm{CH}_{2} \mathrm{O}$ & 40.1 & +10.1 & $34 \%$ & -0.063 & -0.104 \\
$\mathrm{HCN}$ & 39.5 & +10.4 & $36 \%$ & -0.061 & -0.121 \\
$\mathrm{HNC}$ & 39.0 & +10.2 & $35 \%$ & -0.060 & -0.123 \\
$\mathrm{C}_{4} \mathrm{H}_{4} \mathrm{O}$ & 38.8 & +6.1 & $19 \%$ & -0.067 & -0.054 \\
$\mathrm{FCN}$ & 37.9 & +9.3 & $33 \%$ & -0.058 & -0.116 \\
$\mathrm{CH}_{2} \mathrm{~N}_{2}$ & 34.6 & +8.6 & $33 \%$ & -0.047 & -0.096 \\
$\mathrm{CF}_{2} \mathrm{O}$ & 33.3 & +6.1 & $22 \%$ & -0.044 & -0.091 \\
$\mathrm{CH}_{2} \mathrm{CO}$ & 33.2 & +7.3 & $28 \%$ & -0.042 & -0.098 \\
$\mathrm{HF}$ & 32.6 & +6.8 & $26 \%$ & -0.041 & -0.109 \\
$\mathrm{C}_{4} \mathrm{H}_{4} \mathrm{~S}$ & 29.9 & +3.4 & $13 \%$ & -0.032 & -0.247 \\
$\mathrm{HCl}$ & 23.8 & +1.8 & $8 \%$ & -0.004 & -0.111 \\
$\mathrm{HCP}$ & 22.8 & +0.4 & $2 \%$ & -0.003 & -0.034 \\
\hline \hline
\end{tabular}

$\overline{{ }^{a}}$ The interaction energy of $(\mathrm{HF})_{2}-\mathrm{CO}_{2}-\mathrm{Y}$ subtract the interaction energy of $(\mathrm{HF})_{2}-\mathrm{CO}_{2}$ and $\mathrm{CO}_{2}-\mathrm{Y}$.

${ }^{b} P$ ercentage increase in the interaction energy of $(\mathrm{HF})_{2}-\mathrm{CO}_{2}-\mathrm{Y}$ compared with the interaction energy of $\mathrm{CO}_{2}-\mathrm{Y}$.

${ }^{\mathrm{c}} \mathrm{R}(\mathrm{O} \cdots \mathrm{H})$ of $(\mathrm{HF})_{2}-\mathrm{CO}_{2}-\mathrm{Y}$ subtract $\mathrm{R}(\mathrm{O} \cdots \mathrm{H})$ of $(\mathrm{HF})_{2}-\mathrm{CO}_{2}$.

${ }^{\mathrm{d}} \mathrm{R}(\mathrm{C} \cdots \mathrm{Y})$ of $(\mathrm{HF})_{2}-\mathrm{CO}_{2}-\mathrm{Y}$ subtract $\mathrm{R}(\mathrm{C} \cdots \mathrm{Y})$ of $\mathrm{CO}_{2}-\mathrm{Y}$.

We find that the $\mathrm{R}(\mathrm{C}=\mathrm{O})$ bond distance becomes slightly elongated and this is attributed to electron density from the Lewis base transferring into anti-bonding $\mathrm{CO}_{2}$ orbitals (Table $\mathrm{S} 2$ of the supplementary material). ${ }^{44}$ With exception of $\mathrm{CO}_{2}-\mathrm{HCP}$ and $\mathrm{CO}_{2}-\mathrm{HCl}$, we find that the obtuse angle $\left(<180^{\circ}\right)$ of $\mathrm{CO}_{2}$ is orientated on the opposite side of $\mathrm{CO}_{2}$ to Y. Even for the strongest Lewis bases, we find that $\theta(\mathrm{OCO})$ is $>175^{\circ}$, which indicates that $\mathrm{CO}_{2}$ should remain largely linear upon adsorption in MOF materials via C...Y interactions. This result corroborates recent findings by $\mathrm{Wu}$ et al. that large apparent variations in the value of $\theta(\mathrm{OCO})$ for MOF materials with $\mathrm{CO}_{2}$ adsorbed are due to the high orientational disorder of $\mathrm{CO}_{2}$ in the crystal structures rather than any actual chemical changes in $\mathrm{CO}_{2}{ }^{46}$ We find that the $\theta(\mathrm{OCO})$ angle exhibits a clear correlation with the interaction energy, whereas the $\mathrm{R}(\mathrm{C}=\mathrm{O})$ bond distance exhibits a weaker correlation (Figs. S14 and S15 of the supplementary material) ${ }^{44}$

Similar to what was observed in Table II, there is significant variation in the intermolecular distance $\mathrm{R}(\mathrm{C} \cdots \mathrm{Y})$ for a given electron rich atom. For example, $\mathrm{R}(\mathrm{C} \cdots \mathrm{Y})$ is $2.660 \AA$ for $\mathrm{CO}_{2}-\mathrm{O}\left(\mathrm{CH}_{3}\right)_{2}$ and $2.901 \AA$ for $\mathrm{CO}_{2}-\mathrm{CH}_{2} \mathrm{CO}$ despite both molecules binding through an electron rich oxygen atom. It follows that the optimal $\mathrm{R}(\mathrm{C} \cdots \mathrm{Y})$ distance for constructing a $\mathrm{CO}_{2}$ adsorption site cannot be generalized based on the immediate atom of interaction.
TABLE V. CCSD(T)-F12a/VDZ-F12 interaction energies (in $\mathrm{kJ} \mathrm{mol}^{-1}$ ) and selected geometric parameters (in $\AA$ ) for cooperatively bonded complexes of the type $\mathrm{X}_{2}-\mathrm{CO}_{2}-\mathrm{CH}_{2} \mathrm{O}$.

\begin{tabular}{lrrccc}
\hline \hline Molecule & $\begin{array}{c}\text { Int. } \\
\text { energy }\end{array}$ & $\begin{array}{c}\text { Coop. } \\
\text { int. }^{\mathrm{a}}\end{array}$ & Enhancement $^{\mathrm{b}}$ & $\begin{array}{c}\Delta \mathrm{R} \\
(\mathrm{O} \cdots \mathrm{X})^{\mathrm{c}}\end{array}$ & $\begin{array}{c}\Delta \mathrm{R} \\
(\mathrm{C} \cdots \mathrm{O})^{\mathrm{d}}\end{array}$ \\
\hline $\mathrm{AlF}_{3}$ & 105.9 & +28.3 & $37 \%$ & -0.056 & -0.291 \\
$\mathrm{LiCl}$ & 83.7 & +30.7 & $58 \%$ & -0.062 & -0.211 \\
$\mathrm{LiH}$ & 76.5 & +26.9 & $54 \%$ & -0.059 & -0.198 \\
$\mathrm{LiF}$ & 74.4 & +26.9 & $57 \%$ & -0.062 & -0.192 \\
$\mathrm{AlH}_{3}$ & 64.0 & +17.5 & $38 \%$ & -0.108 & -0.211 \\
$\mathrm{HNC}$ & 41.1 & +11.7 & $40 \%$ & -0.073 & -0.101 \\
$\mathrm{HF}$ & 40.1 & +10.1 & $34 \%$ & -0.063 & -0.104 \\
$\mathrm{HCOOH}$ & 35.3 & +6.7 & $24 \%$ & -0.062 & -0.061 \\
$\mathrm{BF}$ & 34.6 & +6.3 & $22 \%$ & -0.066 & -0.085 \\
$\mathrm{HCN}$ & 32.5 & +9.2 & $39 \%$ & -0.082 & -0.072 \\
$\mathrm{OH}_{3}$ & 31.7 & +7.6 & $32 \%$ & -0.071 & -0.073 \\
$\mathrm{BH}_{3}$ & 31.0 & +5.2 & $20 \%$ & -0.085 & -0.080 \\
$\mathrm{HCl}$ & 31.0 & +7.0 & $29 \%$ & -0.073 & -0.073 \\
$\mathrm{CH}_{3} \mathrm{OH}$ & 29.8 & +6.6 & $28 \%$ & -0.059 & -0.082 \\
$\mathrm{H}_{2} \mathrm{O}$ & 28.9 & +6.6 & $29 \%$ & -0.062 & -0.080 \\
$\mathrm{CH}_{4}$ & 14.1 & +0.9 & $7 \%$ & -0.050 & -0.013 \\
\hline \hline
\end{tabular}

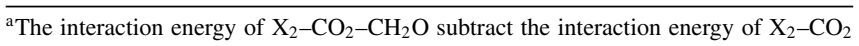
and $\mathrm{CO}_{2}-\mathrm{CH}_{2} \mathrm{O}$.

${ }^{\text {b }}$ Percentage increase in the interaction energy of $\mathrm{X}_{2}-\mathrm{CO}_{2}-\mathrm{CH}_{2} \mathrm{O}$ compared with the interaction energy of $\mathrm{X}_{2} \mathrm{CO}_{2}$.

${ }^{c} \mathrm{R}(\mathrm{O} \cdots \mathrm{X})$ of $\mathrm{X}_{2}-\mathrm{CO}_{2}-\mathrm{CH}_{2} \mathrm{O}$ subtract $\mathrm{R}(\mathrm{O} \cdots \mathrm{X})$ of $\mathrm{X}_{2}-\mathrm{CO}_{2}$.

${ }^{d} \mathrm{R}(\mathrm{C} \cdots \mathrm{O})$ of $\mathrm{X}_{2}-\mathrm{CO}_{2}-\mathrm{CH}_{2} \mathrm{O}$ subtract $\mathrm{R}(\mathrm{C} \cdots \mathrm{O})$ of $\mathrm{CO}_{2}-\mathrm{CH}_{2} \mathrm{O}$.

\section{Cooperative complexes}

In Tables IV and V, we present CCSD(T)-F12a/VDZF12 results for two sets of cooperative complexes, namely, $(\mathrm{HF})_{2}-\mathrm{CO}_{2}-\mathrm{Y}$ and $\mathrm{X}_{2}-\mathrm{CO}_{2}-\mathrm{CH}_{2} \mathrm{O}$. It is not computationally practicable to evaluate all possible combinations of $\mathrm{X}$ and $\mathrm{Y}$ considered in this investigation with the $\operatorname{CCSD}(\mathrm{T})$ F12a/VDZ-F12 method. Hence, to illustrate the effects of cooperative intermolecular interactions we consider just one electron acceptor (HF) with various electron donors and one electron donor $\left(\mathrm{CH}_{2} \mathrm{O}\right)$ with various electron acceptors. The linear structure of the $(\mathrm{HF})_{2}-\mathrm{CO}_{2}$ complex and the perpendicular orientation of $\mathrm{CH}_{2} \mathrm{O}$ relative to the "t-shape" plane of the $\mathrm{CO}_{2}-\mathrm{CH}_{2} \mathrm{O}$ complex, minimize potentially confounding $\mathrm{X} \cdots \mathrm{Y}$ intermolecular interactions. The geometry of $(\mathrm{HF})_{2}-$ $\mathrm{CO}_{2}-\mathrm{CH}_{2} \mathrm{O}$ is shown in Fig. 4 to illustrate the general structure of the cooperative complexes considered with the optimized geometries of all other $\mathrm{X}_{2}-\mathrm{CO}_{2}-\mathrm{CH}_{2} \mathrm{O}$ and $(\mathrm{HF})_{2}-$ $\mathrm{CO}_{2}-\mathrm{Y}$ complexes given in Figs. S16-S20 of the supplementary material. ${ }^{44}$

To limit the computational expense of the $(\mathrm{HF})_{2}-\mathrm{CO}_{2}-$ $\mathrm{Y}$ calculations, we consider only electron donor molecules that permit $C_{2 v}$ symmetry for the cooperative complex. We find that the total interaction energy of these complexes varies from $66.3 \mathrm{~kJ} \mathrm{~mol}^{-1}$ with the strong electron donor $\mathrm{LiF}$ to $22.8 \mathrm{~kJ} \mathrm{~mol}^{-1}$ with the weak electron donor HCP. This wide range is important as it shows that the adsorption energy for a $\mathrm{X}_{2}-\mathrm{CO}_{2}-\mathrm{Y}$ type adsorption site can be readily tuned for optimal adsorption/desorption processes by varying the electron donor functional group. We find that the cooperative interactions of all $(\mathrm{HF})_{2}-\mathrm{CO}_{2}-\mathrm{Y}$ complexes are positive, with the total interaction energy larger than the sum of the individual 

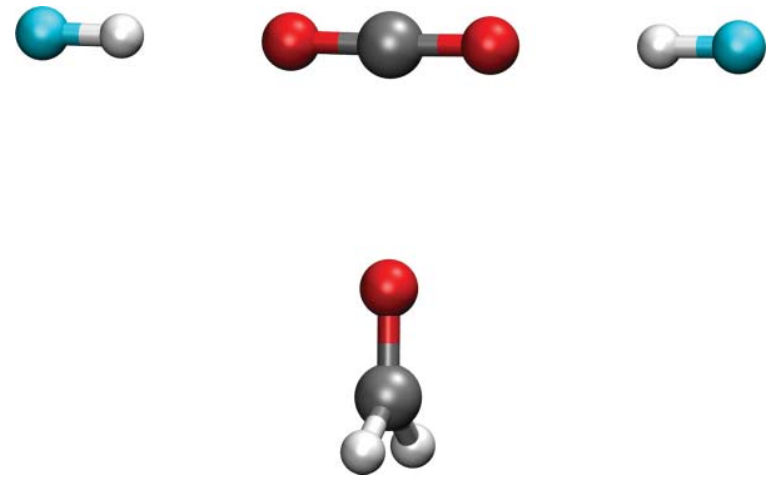

FIG. 4. The CCSD(T)-F12a/VDZ-F12 optimized geometry of $(\mathrm{HF})_{2}-\mathrm{CO}_{2}-$ $\mathrm{CH}_{2} \mathrm{O}$.

interaction energies of the electron donor $\left(\mathrm{CO}_{2}-\mathrm{Y}\right)$ and electron acceptor $\left[(\mathrm{HF})_{2}-\mathrm{CO}_{2}\right]$ complexes. Again, we rationalize this result by considering the NBO atomic charges on $\mathrm{CO}_{2}$ (Table S3 of the supplementary material). ${ }^{44}$ The central carbon atom of $(\mathrm{HF})_{2}-\mathrm{CO}_{2}$ is more electron deficient than in $\mathrm{CO}_{2}$ monomer and hence is more attractive to the electron rich atom of $\mathrm{Y}$. Correspondingly, the terminal oxygen atoms of the $\mathrm{CO}_{2}-\mathrm{Y}$ complex are more electron rich than in $\mathrm{CO}_{2}$ and hence are more attractive to the electron deficient hydrogen atoms of HF.

In general, we find that the magnitude of the cooperative interactions for $(\mathrm{HF})_{2}-\mathrm{CO}_{2}-\mathrm{Y}$ is well correlated with total interaction energy and is large for the more strongly bound complexes and small for the more weakly bound complexes (Fig. S21 of the supplementary material). ${ }^{44}$ The primary geometric effects of these cooperative interactions is to decrease both the $\mathrm{R}(\mathrm{O} \cdots \mathrm{H})$ and $\mathrm{R}(\mathrm{C} \cdots \mathrm{Y})$ intermolecular distances for $(\mathrm{HF})_{2}-$ $\mathrm{CO}_{2}-\mathrm{Y}$ as compared to the respective $(\mathrm{HF})_{2}-\mathrm{CO}_{2}$ and $\mathrm{CO}_{2}-\mathrm{Y}$ complexes. We find that $\Delta \mathrm{R}(\mathrm{O} \cdots \mathrm{H})$ correlates strongly with the magnitude of the cooperative interactions, whereas the correlation between $\Delta \mathrm{R}(\mathrm{C} \cdots \mathrm{Y}$ ) is much weaker (Figs. S22S24 of the supplementary material $).{ }^{44}$

For the $\mathrm{X}_{2}-\mathrm{CO}_{2}-\mathrm{CH}_{2} \mathrm{O}$ complexes, we consider all electron acceptors from Table II except for $\mathrm{C}_{4} \mathrm{H}_{5} \mathrm{~N}, \mathrm{C}_{6} \mathrm{H}_{6}$, $\mathrm{BCl}_{3}$, and $\mathrm{AlCl}_{3}$ as these were too computationally demanding with our present resources with the $\operatorname{CCSD}(\mathrm{T})$ F12a/VDZ-F12 method. We again assume that the diatomic and linear $\mathrm{X}$ molecules bind $\mathrm{CO}_{2}$ in a linear fashion with $\theta(\mathrm{C}=\mathrm{O} \cdots \mathrm{X})$ equal to $180^{\circ}$. For the polyatomic hydrogen bonding molecules, we also restrict the hydrogen bond to be linear and orientate the two $\mathrm{X}$ molecules to be on the opposite side to the $\mathrm{Y}$ molecule. Note that in this orientation, the two $\mathrm{X}$ molecules are on the same side as each other; whereas in Table II, the two X molecules were on opposite sides. For the boron and aluminum hydrides and halides, the $\theta(\mathrm{C}=\mathrm{O} \cdots \mathrm{B})$ or $\theta(\mathrm{C}=\mathrm{O} \cdots \mathrm{Al})$ angle is also restricted to be linear with the two electron deficient groups orientated in an eclipsed position with the in-plane hydrogen or halide trans to the $\mathrm{CH}_{2} \mathrm{O}$ group to minimize potentially confounding $\mathrm{X} \cdots \mathrm{Y}$ intermolecular interactions. We have reoptimized the geometries of these "same side" and "eclipsed" $\mathrm{X}_{2}-\mathrm{CO}_{2}$ complexes and use these reoptimized results when determining the magnitude of the cooperative interactions and change in $\mathrm{R}(\mathrm{O} \cdots \mathrm{X})$ and $\mathrm{R}(\mathrm{C} \cdots \mathrm{Y})$ for $\mathrm{X}_{2}-\mathrm{CO}_{2}-\mathrm{CH}_{2} \mathrm{O}$.
We find that the total interaction energy of the $\mathrm{X}_{2}-\mathrm{CO}_{2}-$ $\mathrm{CH}_{2} \mathrm{O}$ complexes varies from $105.9 \mathrm{~kJ} \mathrm{~mol}^{-1}$ with the strong electron acceptor $\mathrm{AlF}_{3}$ to $14.1 \mathrm{~kJ} \mathrm{~mol}^{-1}$ with the weak electron acceptor $\mathrm{CH}_{4}$. The cooperative interactions of all $\mathrm{X}_{2}-$ $\mathrm{CO}_{2}-\mathrm{CH}_{2} \mathrm{O}$ complexes are positive, with the total interaction energy larger than the sum of the interaction energies of the constituent complexes. Similar to the $(\mathrm{HF})_{2}-\mathrm{CO}_{2}-\mathrm{Y}$ results, the strength of the cooperative interactions for the $\mathrm{X}_{2}-\mathrm{CO}_{2}-$ $\mathrm{CH}_{2} \mathrm{O}$ complexes also appears well correlated with the total interaction energy (Fig. S25 of the supplementary material). ${ }^{44}$ These two results are together important as it shows that the magnitude of cooperative interactions affecting $\mathrm{CO}_{2}$ binding in a potential adsorption site can be tuned via modification of either the electron poor (X) or the electron rich (Y) atoms. Again, the primary effect of these cooperative interactions on the geometry of $\mathrm{X}_{2}-\mathrm{CO}_{2}-\mathrm{CH}_{2} \mathrm{O}$ is to decrease both the $\mathrm{R}(\mathrm{O} \cdots \mathrm{X})$ and $\mathrm{R}(\mathrm{C} \cdots \mathrm{O})$ intermolecular distances as compared to the respective $\mathrm{X}_{2}-\mathrm{CO}_{2}$ and $\mathrm{CO}_{2}-\mathrm{CH}_{2} \mathrm{O}$ complexes. Interestingly, we find that there is essentially no correlation between $\Delta \mathrm{R}(\mathrm{O} \cdots \mathrm{X})$ and the magnitude of the cooperative interactions whereas the correlation between $\Delta \mathrm{R}(\mathrm{C} \cdots \mathrm{O})$ is strong (Figs. S26 and S27 of the supplementary material). ${ }^{44}$

If we consider the intermolecular distances of the $(\mathrm{HF})_{2}-$ $\mathrm{CO}_{2}-\mathrm{Y}$ and $\mathrm{X}_{2}-\mathrm{CO}_{2}-\mathrm{CH}_{2} \mathrm{O}$ results collectively, we observe significant variation in the optimal $\mathrm{R}(\mathrm{O} \cdots \mathrm{X})$ and $\mathrm{R}(\mathrm{C} \cdots \mathrm{Y})$ distances for the different combinations of $\mathrm{X}$ and $\mathrm{Y}$. This, in turn, suggests that when designing the optimal adsorption site for $\mathrm{CO}_{2}$ it is important to consider the effect that cooperative interactions will have on the optimal dimensions of that site. It is worth noting that even if an adsorption site is not deliberately designed to exploit "cooperative interactions" these may still be present from adjacent atoms with potentially unwanted effects.

\section{CONCLUSIONS}

We have calculated the optimized geometry and interaction energy for over 100 different complexes containing $\mathrm{CO}_{2}$ with various combinations of Lewis acids and bases using the explicitly correlated CCSD(T)-F12a/VDZ-F12 method. Our initial calculations on the model complexes $(\mathrm{HF})_{n}-\mathrm{CO}_{2}$ (where $n=1-4,6$ ) showed that this method generally gave interaction energies and the magnitude of the cooperative effect to within a few tenths of a $\mathrm{kJ} \mathrm{mol}^{-1}$ of the $\operatorname{CCSD}(\mathrm{T})$ F12b/VQZ-F12 results.

Overall, we observe only modest changes in the geometric parameters of $\mathrm{CO}_{2}$ upon formation of the various complexes considered in this work. This result indicates that the geometry of $\mathrm{CO}_{2}$ adsorbed in a MOF material should be similar to that of $\mathrm{CO}_{2}$ monomer. We find that when $\mathrm{CO}_{2}$ interacts with a single electron deficient atom via one of the terminal oxygen atoms $\left(\mathrm{X}-\mathrm{CO}_{2}\right)$, the bonded $\mathrm{R}\left(\mathrm{C}=\mathrm{O}_{b}\right)$ distance slightly elongates and the free $\mathrm{R}\left(\mathrm{C}=\mathrm{O}_{f}\right)$ distance slightly contracts. However, when $\mathrm{CO}_{2}$ interacts simultaneously with two electron deficient atoms via both terminal oxygen atoms $\left(\mathrm{X}_{2}-\mathrm{CO}_{2}\right)$, the two bonded $\mathrm{R}\left(\mathrm{C}=\mathrm{O}_{b}\right)$ distances slightly contract. For the $\mathrm{CO}_{2}$-Lewis base complexes, we find that complexation causes a slight increase in the $\mathrm{CO}_{2}$ bond distances 
and a minor deviation from linearity $\left(<5^{\circ}\right)$ in the $\theta(\mathrm{OCO})$ angle.

The interaction energy of the $\mathrm{X}_{2}-\mathrm{CO}_{2}$ complex is found to be less than twice the interaction energy of the $\mathrm{X}-\mathrm{CO}_{2}$ complex. In addition, the $\mathrm{R}(\mathrm{O} \cdots \mathrm{X})$ intermolecular distance for $\mathrm{X}_{2}-\mathrm{CO}_{2}$ is found to be longer than for $\mathrm{X}_{2}-\mathrm{CO}_{2}$. These results are attributed to a decrease in the electron density of the non-bonded oxygen atom of $\mathrm{X}-\mathrm{CO}_{2}$ as compared to $\mathrm{CO}_{2}$ monomer, which in turn makes the non-bonded oxygen atom less attractive to a second Lewis acid molecule.

We investigated two series of cooperative complexes $\left[(\mathrm{HF})_{2}-\mathrm{CO}_{2}-\mathrm{Y}\right.$ and $\left.\mathrm{X}_{2}-\mathrm{CO}_{2}-\mathrm{CH}_{2} \mathrm{O}\right]$ that exhibit simultaneous $\mathrm{CO}_{2}$-Lewis acid $(\mathrm{O} \cdots \mathrm{X})$ and $\mathrm{CO}_{2}$-Lewis base $(\mathrm{C} \cdots \mathrm{Y})$ intermolecular interactions. The interaction energy of these cooperative complexes was found to be larger than the sum of the interaction energies of the constituent $\mathrm{X}_{2}-\mathrm{CO}_{2}$ and $\mathrm{CO}_{2}-\mathrm{Y}$ complexes. Furthermore, the $\mathrm{R}(\mathrm{O} \cdots \mathrm{X})$ and $\mathrm{R}(\mathrm{C} \cdots \mathrm{Y})$ intermolecular distances of the cooperative complexes were found to be shorter than the corresponding intermolecular distances of the constituent complexes. We rationalize these results by considering that formation of $(\mathrm{HF})_{2}-\mathrm{CO}_{2}$ reduces the electron density on the central carbon atom of $\mathrm{CO}_{2}$ making it more attractive to a Lewis base, whereas formation of $\mathrm{CO}_{2}-\mathrm{CH}_{2} \mathrm{O}$ increases the electron density on the terminal oxygen atoms of $\mathrm{CO}_{2}$ making them more attractive to a Lewis acid. We find that the magnitude of this cooperative enhancement of the interaction energy and contraction of the intermolecular distances are correlated to the strength of the various Lewis acids and Lewis bases involved. It follows that the total adsorption strength and optimal dimensions of a $\mathrm{MOF} \mathrm{CO}_{2}$ binding site can in principle be tuned via modification of either electron deficient $(\mathrm{X})$ or electron rich $(\mathrm{Y})$ atoms.

\section{ACKNOWLEDGMENTS}

We thank Cameron J. Kepert for helpful discussions and the University of Waikato High Performance Computing Facility for computer time.

${ }^{1}$ S. Keskin, T. M. van Heest, and D. S. Sholl, ChemSusChem 3, 879 (2010). ${ }^{2}$ C. Lastoskie, Science 330, 595 (2010).

${ }^{3}$ D. B. Dell Amico, F. Calderazzo, L. Labella, F. Marchetti, and G. Pampaloni, Chem. Rev. 103, 3857 (2003).

${ }^{4}$ A. E. Ashley, A. L. Thompson, and D. O'Hare, Angew. Chem., Int. Ed. 48, 9839 (2009)

${ }^{5}$ G. Menard and D. W. Stephan, J. Am. Chem. Soc. 132, 1796 (2010).

${ }^{6}$ J. L. C. Rowsell and O. M. Yaghi, Microporous Mesoporous Mater. 73, 3 (2004).

${ }^{7}$ B. Wang, A. P. Cote, H. Furukawa, M. O'Keeffe, and O. M. Yaghi, Nature (London) 453, 207 (2008)

${ }^{8}$ J. C. Hicks, J. H. Drese, D. J. Fauth, M. L. Gray, G. Qi, and C. W. Jones, J. Am. Chem. Soc. 130, 2902 (2008).

${ }^{9}$ V. Ramanathan, S. S. Iremonger, G. K. H. Shimizu, P. G. Boyd, S. Alavi, and T. K. Woo, Science 330, 650 (2010).

${ }^{10}$ D. M. D. D'Alessandro, B. Smit, and J. R. Long, Angew. Chem., Int. Ed. 49, 6058 (2010).
${ }^{11}$ A. O. Yazaydin, A. I. Benin, S. A. Faheem, P. Jakubczak, J. J. Low, R. R. Willis, and R. Q. Snurr, Chem. Mater. 21, 1425 (2009).

${ }^{12}$ N. A. Ramsahye, G. Maurin, S. Bourrelly, P. L. Llewellyn, T. Devic, C. Serre, T. Loiseau, and G. Ferey, Adsorption 13, 461 (2007).

${ }^{13}$ P. D. C. Dietzel, V. Besikiotis, and R. Blom, J. Mater. Chem. 19, 7362 (2009).

${ }^{14}$ D. Britt, H. Furukawa, B. Wang, T. G. Glover, and O. M. Yaghi, Proc. Natl. Am. Soc. U.S.A. 106, 20637 (2009).

${ }^{15}$ V. Ramanathan, S. S. Iremonger, K. W. Dawson, and G. K. H. Shimizu, Chem. Commun. 2009, 5230.

${ }^{16}$ A. Demessence, D. M. D'Alessandro, M. L. Foo, and J. R. Long, J. Am. Chem. Soc. 131, 8784 (2009).

${ }^{17}$ M. A. Blatchford, P. Raveendran, and S. L. Wallen, J. Am. Chem. Soc. 124, 14818 (2002).

${ }^{18}$ S. L. Raveendran and P. Wallen, J. Am. Chem. Soc. 124, 7274 (2002).

${ }^{19}$ P. Van Ginderen, W. A. Herrebout, and B. J. van der Veken, J. Phys. Chem. A 107, 5391 (2003).

${ }^{20}$ M. A. Blatchford, P. Raveendran, and S. L. Wallen, J. Phys. Chem. A 107, 10311 (2003).

${ }^{21}$ K. H. Kim and Y. Kim, J. Phys. Chem. A 112, 1596 (2008).

${ }^{22}$ S. L. Raveendran and P. Wallen, J. Phys. Chem. B 107, 1473 (2003).

${ }^{23}$ M. Saharay and S. Balasubramanian, J. Phys. Chem. B. 110, 3782 (2006).

${ }^{24}$ R. Rivelino, J. Phys. Chem. A 112, 161 (2008).

${ }^{25}$ J. C. Meredith, K. P. Johnston, J. M. Seminario, S. G. Kazarian, and C. A. Eckert, J. Phys. Chem. 100, 10837 (1996).

${ }^{26}$ K. D. Vogiatzis, A. Mavrandonakis, W. Klopper, and G. E. Froudakis, ChemPhysChem 10, 374 (2009).

${ }^{27}$ A. Torrisi, C. Mellot-Draznieks, and R. G. Bell, J. Chem. Phys. 130, 194703 (2009).

${ }^{28}$ A. Torrisi, C. Mellot-Draznieks, and R. G. Bell, J. Chem. Phys. 132, 044705 (2010).

${ }^{29}$ G. Adler, T. B. Knizia, and H.-J. Werner, J. Chem. Phys. 127, 221106 (2007).

${ }^{30}$ MOLPRO, a package of ab initio programs designed by H.-J. Werner and P. J. Knowles, version 2010.1, R. D. Amos, A. Bernhardsson, A. Berning et al.

${ }^{31}$ K. A. Peterson, T. B. Adler, and H.-J. Werner, J. Chem. Phys. 128, 084102 (2008).

32 J. R. Lane and H. G. Kjaergaard, J. Chem. Phys. 131, 034307 (2009).

${ }^{33}$ K. de Lange and J. Lane, J. Chem. Phys. 134, 034301 (2011).

${ }^{34}$ F. R. Manby, J. Chem. Phys. 119, 4607 (2003).

${ }^{35}$ H.-J. Werner, T. B. Adler, and F. R. Manby, J. Chem. Phys. 126, 164102 (2007).

${ }^{36}$ F. Weigend, A. Köhn, and C. Hättig, J. Chem. Phys. 116, 3175 (2002).

${ }^{37}$ F. Weigend, Phys. Chem. Chem. Phys. 4, 4285 (2002).

${ }^{38}$ K. E. Yousaf and K. A. Peterson, J. Chem. Phys. 129, 184108 (2008).

${ }^{39}$ O. Marchetti and H.-J. Werner, J. Phys. Chem. A 113, 11580 (2009).

${ }^{40} \mathrm{~S}$. Ten-no, Chem. Phys. Lett. 398, 56 (2004).

${ }^{41}$ D. P. Tew and W. Klopper, J. Chem. Phys. 125, 094302 (2006).

${ }^{42}$ D. Feller, K. A. Peterson, and J. G. Hill, J. Chem. Phys. 133, 184102 (2010).

${ }^{43}$ M. J. Frisch, G. W. Trucks, H. B. Schlegel et al., GAussian 09, Revision A.1, Gaussian, Inc., Wallingford, CT, 2009.

${ }^{44}$ See supplementary material at http://dx.doi.org/10.1063/1.3624363 for images of all complexes optimized with the CCSD(T)-F12a/VDZ-F12 method; XY correlation plots for interaction energy and cooperative interaction energy; XY correlation plots for interaction energy and selected intramolecular geometric parameters; $\mathrm{XY}$ correlation plots for cooperative interactive energy and selected intermolecular geometric parameters; selected B3LYP/aug-cc-pVTZ NBO atomic charges and the magnitude of charge transfer.

${ }^{45}$ G. Knizia, T. B. Adler, and H.-J. Werner, J. Chem. Phys. 130, 054104 (2009).

${ }^{46} \mathrm{H}$. Wu, J. M. Simmons, G. Srinivas, W. Zhou, and T. Yildirim, J. Phys. Chem. Lett. 1, 1946 (2010). 